\title{
Knowledge, attitude and practices: assessing maternal and child health care handbook intervention in Vietnam
}

\author{
Hirotsugu Aiga ${ }^{1,2^{*}}$, Vinh Duc Nguyen ${ }^{3}$, Cuong Dinh Nguyen ${ }^{4}$, Tho Thi Thi Nguyen ${ }^{5}$ and Lien Thi Phuong Nguyen ${ }^{5}$
}

\begin{abstract}
Background: Maternal and Child Health (MCH) Handbook, an integrated MCH home-based record, was piloted in four provinces of Vietnam (Dien Bien, Hoa Binh, Thanh Hoa and An Giang). The study is aimed at assessing the changes in pregnant women's behavior towards the frequencies of their antenatal care service utilizations and their subsequent breastfeeding practices up to six months of age, through the MCH Handbook intervention. This is because the levels of pregnant women's knowledge, attitude and practices (KAP) towards their antenatal care service utilizations and exclusive breastfeeding practices have been previously neither analyzed nor reported in relation to MCH home-based records in the country.
\end{abstract}

Methods: To compare pre-intervention baseline in 2011, post-intervention data were collected in 2013. Structured interviews were conducted with randomly selected 810 mothers of children 6-18 months of age in the four provinces. A focus group discussion among mothers in each of four provinces was conducted.

Results: There was no significant difference in pregnant women's knowledge about the need for $\geq 3$ antenatal care visits between pre- and post-interventions. Yet, the proportion of pregnant women who made $\geq 3$ antenatal care visits in post-intervention was significantly higher than in pre-intervention. Thus, MCH Handbook is likely to have contributed to practicing $\geq 3$ antenatal care visits, by changing their attitude. The proportion of mothers who know the need for exclusive breastfeeding necessary during the initial six months significantly increased between pre- and post-interventions. The proportion of those practicing exclusive breastfeeding significantly increased between pre- and post-interventions, too. Thus, MCH Handbook is likely to have contributed to the increase in both knowledge about and practices of exclusive breastfeeding.

Conclusion: The results of study imply that MCH Handbook contributed to the increase in pregnant women's practices of $\geq 3$ antenatal care visits and in their knowledge about and practice of exclusive breastfeeding. While there is room for improvement in the level of its data recording, the study confirmed that MCH Handbook plays a catalytic role in ensuring a continuum of maternal, newborn and child care. Note that this study is the first study that attempted to estimate pregnant women's behavioral changes through MCH Handbook intervention in Vietnam.

Keywords: Maternal, newborn and child health, Home-based records, Maternal and child health handbook, Knowledge, attitude and practice

\footnotetext{
* Correspondence: aiga.hirotsugu@jica.go.jp

${ }^{1}$ Human Development Department, Japan International Cooperation Agency

(JICA), 3rd floor, Nibancho Center Building, 5-25 Niban-cho, Chiyoda-ku,

Tokyo 102-8012, Japan

${ }^{2}$ Department of Global Health, Milken Institute School of Public Health, The

George Washington University, 950 New Hampshire Ave, NW, 7th floor,

Washington DC 20052, USA

Full list of author information is available at the end of the article
}

\section{$\int$ Biomed Central}

(c) 2016 Aiga et al. Open Access This article is distributed under the terms of the Creative Commons Attribution 4.0 International License (http://creativecommons.org/licenses/by/4.0/), which permits unrestricted use, distribution, and reproduction in any medium, provided you give appropriate credit to the original author(s) and the source, provide a link to the Creative Commons license, and indicate if changes were made. The Creative Commons Public Domain Dedication waiver (http://creativecommons.org/publicdomain/zero/1.0/) applies to the data made available in this article, unless otherwise stated. 


\section{Background}

Maternal and Child Health (MCH) Handbook is an integrated home-based record of health conditions of and health service utilizations by both a mother and her child, throughout pregnancy, delivery, postnatal, newborn and childhood stages. MCH Handbook has been increasingly drawing an international attention as an effective tool for $\mathrm{MCH}$ self-monitoring and subsequent timely and adequate $\mathrm{MCH}$ service utilizations. For instance, it was reported that ownership of $\mathrm{MCH}$ Handbook was significantly associated with having delivery assisted by trained personnel, receiving maternal care, and completing 12 doses of child immunizations for seven diseases, in Indonesia [1]. Having been expected to play a catalytic role in ensuring a continuum of seamless maternal, newborn and child care $[1,2]$ for achieving towards the Millennium Development Goal (MDG) 4 and 5, MCH Handbook has been implemented as an essential part of maternal and child health system in both developing and developed countries $[3,4]$. MCH Handbook promotes health education and serves as the technically reliable source of the information for referring a patient to a higher/lower health facility and for collecting data in health surveys [5].

Vietnam, one of the eight 'On-Track' countries in both Millennium Development Goals (MDGs) 4 and 5, is making a successful progress in reducing maternal mortality ratio by $78 \%$ from 233 in 1990 to 49 per 100,000 livebirths in 2013, and under-five mortality rate by $53 \%$ from 51 in 1990 to 24 per 1,000 livebirths in 2013 [6]. Yet, these reductions have been achieved nationwide in a less equal manner. The discrepancies in both maternal mortality ratio and under-five mortality rate between provinces are significant. For instance, under-five mortality rate in Central Highland region (39.8) is 2.9 times and 1.7 times higher than respectively South East region (13.5) and national average (24) [7]. Similarly, maternal mortality ratio in North West Region (169) is 2.5 times higher than national average (67) [8]. Thus, to realize more equally lower under-five-mortality rate and maternal mortality ratio, it is key to ensure adequately frequent antenatal checkups and access to neonatal and child health care services in the provinces where $\mathrm{MCH}$ services are less accessible.

To address these challenges, the Vietnamese Ministry of Health $(\mathrm{MoH})$, in collaboration with Japan International Cooperation Agency (JICA), implemented the standardized $\mathrm{MCH}$ Handbook for its nationwide scaling-up, through its field-piloting in four provinces with different profiles (Dien Bien, Hoa Binh, Thanh Hoa and An Giang) from 2011 to 2014. The standardized MCH Handbook was composed of recording section and guidance section for respective maternal and child health stages, i.e. pregnancy, delivery, postnatal, newborn and childhood. As of 30 September 2014, a total of 552,204 pregnant women and mothers with infants registered at local commune health centers in the four provinces received and used the $\mathrm{MCH}$ Handbooks.

This study is aimed at estimating the changes in pregnant women's behavior towards the frequencies of their antenatal care service utilizations and their subsequent exclusive breastfeeding practices up to six months of age, through the $\mathrm{MCH}$ Handbook interventions in the four provinces of Vietnam. The levels of pregnant women's knowledge, attitude and practices (KAP) towards their antenatal care service utilizations and exclusive breastfeeding practices have been previously neither analyzed nor reported in relation to $\mathrm{MCH}$ home-based records in the country. Thus, this study serves as the first assessment of pregnant women's behavioral changes through the interventions of $\mathrm{MCH}$ home-based records (incl. child vaccination cards) in Vietnam.

\section{Methods}

In this study, the changes in pregnant women's behaviors toward antenatal care service utilizations and subsequent exclusive breastfeeding practices through $\mathrm{MCH}$ Handbook intervention were assessed, by comparing between pre-intervention and post-intervention data.

\section{MCH-Handbook-piloted provinces as study areas}

As the technical collaboration between the $\mathrm{MoH}$ and JICA, $\mathrm{MCH}$ Handbook was piloted in four of 64 provinces in Vietnam (Dien Bien, Hoa Binh, Thanh Hoa and An Giang). These four were selected as the pilot intervention provinces, so as to ensure inter-provincial diversities in public health profile and socioeconomic characteristics (Table 1) [7-11], considering the future nationwide scaling-up of $\mathrm{MCH}$ Handbook. Dien Bien is one of the least developed provinces located in the mountainous area bordered with Lao People's Democratic Republic. A substantial proportion of the populations of Dien Bien speak primarily the languages of local ethnic minorities. Hoa Binh is another province where ethnic minority populations account for greater proportion. Thanh Hoa has the third greatest population and the fifth largest territory of all the 64 provinces, by ranging from coastal areas to mountainous areas. An Giang is one of the southern provinces where private sector is well developed in health service delivery.

An $\mathrm{MCH}$ Handbook has been handed to each pregnant woman, being followed by its face-to-face verbal guidance by a health worker upon the initial antenatal care visit, at 1,141 commune health centers in the four provinces. A phased implementation approach was employed for $\mathrm{MCH}$ Handbook intervention, to ensure quality of training of health workers on contents of $\mathrm{MCH}$ Handbook, guidance to pregnant women, and monitoring and supervision. All the 59 districts in the four provinces were divided into three groups (18 Phase-1 districts, 21 
Table 1 Characteristics of four provinces in which MCH Handbook was piloted

\begin{tabular}{|c|c|c|c|c|c|}
\hline \multirow[t]{2}{*}{ Province } & \multicolumn{4}{|c|}{ Four piloted provinces } & \multirow[t]{2}{*}{ Vietnam } \\
\hline & Dien Bien & Hoa Binh & Thanh Hoa & An Giang & \\
\hline Area $\left(\mathrm{km}^{2}\right)^{\mathrm{a}}$ & 9,563 & 4,608 & 11,132 & 3,537 & 330,972 \\
\hline Population (in thousand) [2014] ${ }^{\mathrm{a}}$ & 527 & 808 & 3,477 & 2,155 & 89,709 \\
\hline Infant mortality rate (per 1,000 live births) [2013] ${ }^{b}$ & 35.5 & 17.7 & 16.0 & 15.1 & 15.3 \\
\hline Under-five mortality rate (per 1,000 live births) [2013] ${ }^{\mathrm{b}}$ & 54.9 & 26.6 & 24.1 & 22.7 & 23.1 \\
\hline Maternal mortality ratio (per 100,000 live births) $[2012]^{c}$ & 64.38 & 41.6 & $70[2010]$ & 29 & 61.9 \\
\hline Female adult literacy rate $\geq 15$ years of age (\%) [2009] ${ }^{d}$ & 54.8 & 93.2 & 92.7 & 85.7 & 91.4 \\
\hline Poverty rate (\%) [2013] & 35.06 & 18.7 & 13.13 & 4.96 & 7.8 \\
\hline Proportion of ethnic minority (\%) [2009] ${ }^{d}$ & 81.1 & 73.6 & 17.6 & 5.3 & 14.3 \\
\hline
\end{tabular}

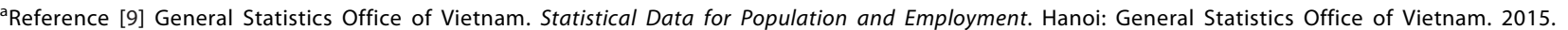
http://www.gso.gov.vn (accessed June 2015)

${ }^{\mathrm{b}}$ Reference [7] Ministry of Planning and Investment. The 1/4/2013 time-point population change and family planning survey- major findings: annex 9. Hanoi: Ministry of Planning and Investment. 2013. http://www.gso.gov.vn (accessed June 2015)

'Reference [8] Ministry of Health. Annual report of provincial health services. Hanoi: Ministry of Health. 2015

${ }^{d}$ Reference [10] Central Population and Housing Census Steering Committee. The 2009 Vietnam Population and Housing Cencus. Hanoi: Central Population and Housing Census Steering Committee. 2010

e Reference [11] Ministry of Labor, Invalids and Social Affairs. Decision no. 529 on 05/06/2014 - Approving the result of survey, revision on poor household and near poor household in 2013. Hanoi: Ministry of Labor, Invalids and Social Affairs. 2013

Phase-2 districts, and 20 Phase-3 districts) for the phased implementation approach. I.e. MCH Handbook intervention started earliest in Phase-1 districts in January 2012, while starting in Phase-2 and Phase-3 districts later respectively in August 2012 and June 2013.

Pre-aggregated baseline data on pregnant women's knowledge about maternal health, utilization of its services, and breastfeeding practices had been available for the four provinces. The pre-aggregated baseline data had been collected by three-stage random sampling (first district selection, second commune selection, and third household selection), ensuring provincially representative sample size [12]. Therefore, in this study, post-intervention cross-sectional data were collected by quantitative survey in the same manner, to compare them with the baseline. To complement data gap due to limitedly available quantitative data, qualitative data were collected by conducting a focus group discussion among mothers in each of four provinces.

\section{Sample size}

Post-intervention data were collected through structured interviews with mothers and observations of their $\mathrm{MCH}$ Handbooks in the four provinces during the period from 1 July to 15 August 2013. To enable provincially representative proportions to be estimated, the sample size was calculated with $\alpha$ (error) $=0.05,1-\beta$ (power) $=0.75$ and $d$ $($ precision $)=0.1$. The proportion of pregnant women who bring $\mathrm{MCH}$ Handbooks for antenatal care visits and other key variables were unable to be reasonably anticipated. This is because the levels of pregnant women's behavioral changes towards their antenatal care service utilizations and exclusive breastfeeding practices through $\mathrm{MCH}$ Handbook were not pre-known as it had never previously been implemented in the four provinces. Therefore, we assumed that those proportions could be $50 \%$, under which the greatest sample size is required. This assumption helped the study ensure statistical representativeness, while admitting possible oversampling risks. Moreover, 1.2 of design effect was multiplied by the sample size [13], due to the following sampling procedure. Then, 200 mothers (former pregnant women) were determined to be the final sample size for each of three provinces (Dien Bien, Hoa Binh and An Giang), ensuring provincially representative estimates. The sample size for Thanh Hoa was increased by $5 \%$ compared with other three provinces, considering an additional sampling stage only for Thanh Hoa. Thus, total of 810 mothers $(=200$ mothers $\times 3$ provinces +210 mothers $\times 1$ province) were set as the final sample size for the post-intervention survey.

\section{Sampling procedure}

Three steps were taken for selection of target mothers. First, to ensure minimum adequate period of time during which pregnant women get familiar with and actually use $\mathrm{MCH}$ Handbook, 18 Phase-1 districts were selected out of 59 districts. All the 10 Phase-1 districts in three of the four study provinces (Dien Bien, Hoa Binh and An Giang) were selected. For Thanh Hoa, the study province with the largest number of districts and populations, three of eight Phase-1 districts were randomly selected, due to both temporal and financial constraints available for the study. Thus, a total of 13 districts were selected in the four provinces.

Second, eight to nine communes were further randomly selected in each of 10 Phase-1 districts of Dien Bien, Hoa Binh and An Giang. For Thanh Hoa, 30 
communes were randomly selected from three selected Phase-1 districts. This $20 \%$ increase in the number of selected communes was conducted due to additional district-level sampling stage only for Thanh Hoa. Note that, to have provincially representative estimates for Thanh Hoa, 1.05 was applied as the minimum design effect $(200 \times 1.05=210)$ instead of 1.2 as recommended by WHO [13] due to the aforementioned constraints.

Third, eight households were further selected in each of 25 communes in Dien Bien, Hoa Binh and An Giang $(8 \times 25=200)$. Seven households were selected in each of 30 communes $(210=30 \times 7)$ in Thanh Hoa. The initial bulky batch of $\mathrm{MCH}$ Handbook distribution in Phase-1 districts was launched in January 2012 and completed in May 2012, to fully cover all existing pregnant women. Then, $\mathrm{MCH}$ Handbook distribution became routine-based, i.e. at the initial antenatal care visit of any newly pregnant women. In rural Vietnam, women notice their pregnancy typically two month after conception
[14]. Given this reality, children of the mothers who received $\mathrm{MCH}$ Handbooks during the initial batch period in Phase-1 districts were estimated to be born between January 2012 and January 2013 and become between 6 and 18 months of age at the time of this postintervention survey (i.e. July - August 2013). Therefore, target households were selected from the lists of households with children 6-18 months of age living in the communes, by systematic random sampling. The range of children's dates of birth in the post-intervention survey (January 2012 - January 2013) largely corresponds to that of pre-intervention baseline (January 2012 - December 2012). This enabled the study to estimate the change in antenatal care seeking behavior between pre- and postinterventions in a more precise manner, by matching interviewees' profiles. To estimate the change in breastfeeding practices, we compared between mothers of children under three years of age as of 2011 (pre-intervention) and mothers selected as of 2013 (post-intervention) (Table 2)

Table 2 Characteristics of pre-intervention pregnant women/mothers and post-intervention mothers

\begin{tabular}{|c|c|c|c|c|c|c|c|c|c|c|c|c|c|c|}
\hline & \multicolumn{4}{|c|}{ Pre-intervention in $2011^{a}$} & \multicolumn{10}{|c|}{ Post-intervention in $2013^{b}$} \\
\hline & \multicolumn{2}{|c|}{$\begin{array}{l}\text { Pregnant } \\
\text { women }^{c} \\
(N=800)\end{array}$} & \multicolumn{2}{|c|}{ 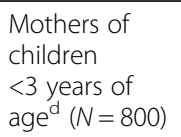 } & \multicolumn{2}{|c|}{$\begin{array}{l}\text { Dien Bien } \\
(n=200)\end{array}$} & \multicolumn{2}{|c|}{$\begin{array}{l}\text { Hoa Binh } \\
(n=200)\end{array}$} & \multicolumn{2}{|c|}{$\begin{array}{l}\text { Thanh Hoa } \\
(n=210)\end{array}$} & \multicolumn{2}{|c|}{$\begin{array}{l}\text { An Giang } \\
(n=200)\end{array}$} & \multicolumn{2}{|c|}{$\begin{array}{l}\text { Total } \\
(N=810)\end{array}$} \\
\hline & $n$ & (\%) & $n$ & (\%) & $n$ & (\%) & $n$ & (\%) & $n$ & (\%) & $n$ & (\%) & $n$ & (\%) \\
\hline \multicolumn{15}{|l|}{ Age } \\
\hline $15-34$ years of age & 735 & $(92 \%)$ & 628 & $(78 \%)$ & 185 & (93\%) & 190 & (95\%) & 177 & (84 \%) & 178 & (89 \%) & 730 & (90 \%) \\
\hline$>34$ years of age & 65 & (8\%) & 172 & $(22 \%)$ & 15 & $(8 \%)$ & 10 & $(5 \%)$ & 33 & $(16 \%)$ & 22 & $(11 \%)$ & 80 & $(10 \%)$ \\
\hline \multicolumn{15}{|l|}{ Ethnicity } \\
\hline Kinh & 475 & $(59 \%)$ & 500 & $(63 \%)$ & 61 & (31\%) & 39 & $(20 \%)$ & 201 & (96 \%) & 200 & $(100 \%)$ & 501 & $(61.9 \%)$ \\
\hline Ethnic minority & 325 & $(41 \%)$ & 300 & (37\%) & 139 & $(70 \%)$ & 161 & $(81 \%)$ & 9 & $(4 \%)$ & 0 & (0 \%) & 309 & (38.1\%) \\
\hline \multicolumn{15}{|l|}{ Vietnamese-speaking ability } \\
\hline Fluent & 760 & (95\%) & 765 & (96\%) & 190 & (95\%) & 198 & (99\%) & 210 & $(100 \%)$ & 200 & $(100 \%)$ & 798 & (99\%) \\
\hline Not fluent/unable to speak & 40 & $(5 \%)$ & 35 & $(4 \%)$ & 10 & $(5 \%)$ & 2 & $(1 \%)$ & 0 & $(0 \%)$ & 0 & (0 \%) & 12 & $(1 \%)$ \\
\hline \multicolumn{15}{|l|}{ Education } \\
\hline No school education & 59 & $(7 \%)$ & 25 & (3 \%) & 14 & (7 \%) & 1 & $(1 \%)$ & 0 & $(0 \%)$ & 4 & $(2 \%)$ & 19 & $(2 \%)$ \\
\hline Primary school & 144 & $(18 \%)$ & 134 & $(17 \%)$ & 32 & $(16 \%)$ & 12 & $(6 \%)$ & 3 & (1\%) & 42 & $(21 \%)$ & 89 & (11\%) \\
\hline Secondary school & 322 & $(40 \%)$ & 297 & (37\%) & 58 & $(29 \%)$ & 65 & (33\%) & 57 & $(27 \%)$ & 80 & $(40 \%)$ & 260 & (32\%) \\
\hline High school & 174 & (22\%) & 254 & (32\%) & 65 & (33\%) & 91 & $(46 \%)$ & 84 & $(40 \%)$ & 52 & $(26 \%)$ & 292 & $(36 \%)$ \\
\hline Vocational school or higher & 101 & $(13 \%)$ & 90 & (11\%) & 31 & $(16 \%)$ & 31 & $(16 \%)$ & 65 & $(31 \%)$ & 22 & $(11 \%)$ & 149 & $(18 \%)$ \\
\hline \multicolumn{15}{|l|}{ Economic status } \\
\hline Non-poor & 619 & $(77 \%)$ & 684 & $(86 \%)$ & 170 & $(85 \%)$ & 71 & (71\%) & 89 & (89 \%) & 183 & (92\%) & 513 & (86 \%) \\
\hline Poor/near-poor & 181 & $(23 \%)$ & 116 & (14\%) & 30 & $(15 \%)$ & 29 & $(29 \%)$ & 11 & $(11 \%)$ & 17 & (9\%) & 87 & $(15 \%)$ \\
\hline
\end{tabular}

[Remarks]

aPre-intervention baseline data had been collected also in Dien, Bien, Hoa Binh, Thanh Hoa and An Giang provinces in 2011, prior to the launching MCH Handbook intervention [14]

${ }^{\mathrm{b}}$ Mothers of children who were born between January 2012 and January 2013 [as of July-August 2013 after MCH Handbook intervention]

'Pregnant women whose expected dates of delivery were between January and December 2012, for comparison with post-intervention mothers on antenatal care visits

${ }^{d}$ Mothers of children $<3$ years of age as of 2011 , for comparison with post-intervention mothers on breastfeeding practices 
[12]. Note that data comparability between pre- and postinterventions were ensured due to the equally provinciallyrepresentative datasets, though pregnant women and mothers sampled differed between them.

\section{Data collection}

Questions about knowledge, attitude and practices of antenatal care service utilizations and exclusive breastfeeding practices in relation to use of $\mathrm{MCH}$ Handbook were asked during structured interviews. To determine whether antenatal care visits and exclusive breastfeeding practices were correctly conducted, interviewees' verbal responses were double-checked against their records in $\mathrm{MCH}$ Handbook. When mothers insisted their antenatal care visits or exclusive breastfeeding practices despite non-recording in $\mathrm{MCH}$ Handbook, their responses were further double-checked against their family members' observations and views. Moreover, the level of recording data on $\mathrm{MCH}$ Handbooks was measured through the observations of the $\mathrm{MCH}$ Handbooks.

\section{Data analysis}

Data obtained in the post-intervention cross-sectional survey were analyzed, using SPSS for Windows version 22 (IBM/SPSS Inc., Chicago, USA). Statistical comparison between pre- and post-intervention data was conducted, using R version 3.2.2 (The R Foundation, Vienna, Austria). To assess the difference in the proportion of categorical variables between pre- and post-interventions, Chi-square test was employed. KAP model [15] was applied to estimate behavior changes in antenatal care service utilizations and exclusive breastfeeding practices through $\mathrm{MCH}$ Handbook intervention.

\section{Qualitative data collection}

A focus group discussion (FGD) was conducted in a rural commune of each province. A focus group was composed of five or six mothers who received $\mathrm{MCH}$ Handbooks during their pregnancies and later gave births between January 2012 and January 2013. Openended questions on the use of $\mathrm{MCH}$ Handbook were asked them. The contents of FGDs were transcribed and typed into Microsoft Word 2010 (Microsoft, Redmond, USA). Then, key phrases were coded and categorized for further analyses.

\section{Ethical consideration}

The study proposal along with the questionnaire for structured interviews and open-ended questions for FGDs were reviewed from ethical perspectives and authorized by the Vietnamese $\mathrm{MoH}$. As a result, the $\mathrm{MoH}$ officially concluded that that ethical approval was deemed unnecessary because the level of invasiveness of the study was low enough. Prior to conducing structured interviews and FGDs, informed consent to participate in the study was obtained verbally from mothers of children 6-18 months of age. The illiterate participant mothers expressed their reluctance to sign on the consent document which they did not understand. Considering their reluctance derived from likely inferiority complex, written consent was not obtained from all the participants.

\section{Results}

Table 2 presents the characteristics of mothers interviewed in the survey (post-intervention), in comparison with those of pregnant women and mothers of children under three years of age interviewed in 2011 (pre-intervention). Overall, socioeconomic and socio-demographic status of the interviewees were homogeneous between pre- and post-interventions. Table 3 presents the KAP variables in a manner that compares between pre- and post-interventions. The variables related to the use of $\mathrm{MCH}$ Handbook were measured only in post-intervention, as $\mathrm{MCH}$ Handbooks had been neither distributed nor used at the time of pre-intervention. Moreover, in preintervention, the two variables related to knowledge about antenatal care and breastfeeding had been measured among pregnant women, while another two variables related to their practices had been measured among mothers of children. This is because there was always risk that knowledge at time of pregnancy does not necessarily ensure their practices until and after delivery.

\section{KAP towards antenatal care}

Top-half of Table 3 shows the KAP variables in relation to women's antenatal care seeking behaviors in both preintervention and post-intervention. Prior to $\mathrm{MCH}$ Handbook intervention, the proportion of pregnant women and mothers who correctly know at least three antenatal care visits are necessary during pregnancy had been as high $(91.9 \%)$ as post-intervention (93.7\%). This may imply that its slight increase from 91.9 to $93.7 \%(P=0.1559)$ is not a statistically meaningful difference associated with $\mathrm{MCH}$ Handbook intervention, but rather a possible error derived from difference in sampling variance between preand post-intervention surveys. The statement made by a 28-year old mother of two children at the FGD in Dien Bien supports this inference:

\section{I had known that I must make at least three} antenatal care visits to the nearest commune health center since my first pregnancy. For instance, when I was pregnant and gave the birth to my first child, I learned from one nurse that I need to have at least three antenatal checkups, even before receiving the MCH Handbook. 
Table 3 Characteristics of pre-intervention pregnant women/mothers and post-intervention mothers

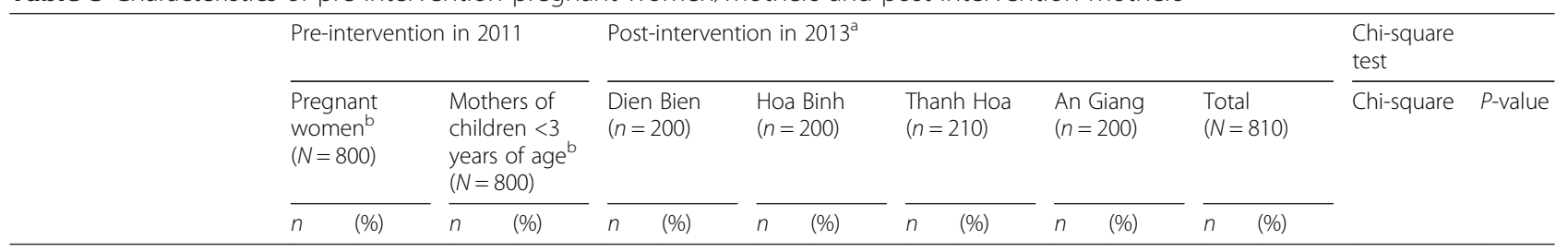

Antenatal care seeking behavior

Knowledge: Know a need for $\geq 3$ ANC visits

\begin{tabular}{|c|c|c|c|c|c|c|c|c|c|c|c|c|c|c|c|c|}
\hline Know & 735 & (91.9\%) & [n.a.] & [n.a.] & 179 & (89.5\%) & 186 & (93.0 \%) & 202 & (96.0\%) & 192 & (96.0 \%) & 759 & (93.7\%) & 2.0132 & 0.1559 \\
\hline Don't know & 65 & (8.1\%) & [n.a.] & [n.a.] & 21 & $(10.5 \%)$ & 14 & $(7.0 \%)$ & 8 & (4.0 \%) & 8 & (4.0 \%) & 51 & $(6.3 \%)$ & & \\
\hline
\end{tabular}

Attitude: Will take/took MCH Handbook for ANC visits ${ }^{\mathrm{a}}$

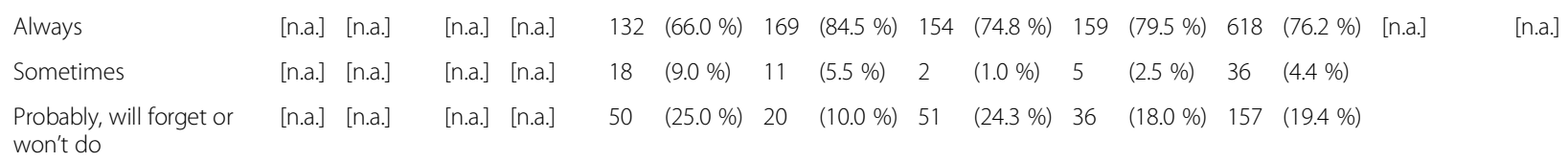

Practice 1: Made $\geq 3$ ANC visits, in practice

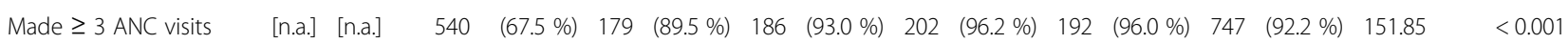

$\begin{array}{lllllllllllllll}\text { Made only < } 3 \text { ANC } & \text { [n.a.] } & \text { [n.a.] } & 260 & (32.5 \%) & 21 & (10.5 \%) & 14 & (7.0 \%) & 8 & (8 \%) & 8 & (4.0 \%) & 63 & (7.8 \%)\end{array}$

visits

Practice 2: $\geq 3$ ANC recorded in MCH Handbook by HWs ${ }^{\mathrm{a}}$

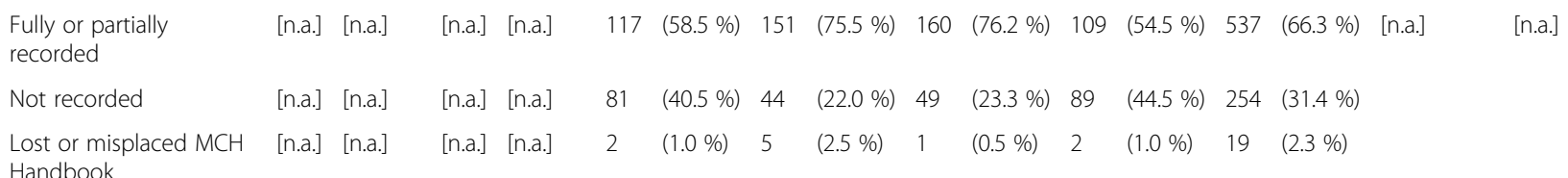

Breastfeeding practices

Knowledge: Know exclusive breastfeeding for 24 months

\begin{tabular}{|c|c|c|c|c|c|c|c|c|c|c|c|c|c|c|c|c|}
\hline Know & 529 & (66.1\%) & [n.a.] & [n.a.] & 170 & (85.0\%) & 132 & (66.0\%) & 139 & (66.2 \%) & 132 & (66.1\%) & 702 & (86.7 \%) & \multirow[t]{2}{*}{92.219} & \multirow[t]{2}{*}{$<0.001$} \\
\hline Don't know & 271 & (33.9\%) & [n.a.] & [n.a.] & 30 & (15.0\%) & 68 & (34.0\%) & 71 & (33.8 \%) & 68 & (33.9\%) & 108 & (13.3\%) & & \\
\hline ttitude: Will take/took MC & and & for $c h$ & ild hed & Ith che & & & & & & & & & & & & \\
\hline Always & [n.a.] & [n.a.] & [n.a.] & [n.a.] & 170 & (85.1\%) & 147 & (73.7 \%) & 146 & (69.6\%) & 153 & (76.3 \%) & 617 & (76.5 \%) & \multirow[t]{3}{*}{ [n.a.] } & \multirow[t]{3}{*}{ [n.a.] } \\
\hline Sometimes & [n.a.] & [n.a.] & [n.a.] & [n.a.] & 5 & (2.3\%) & 14 & (7.0 \%) & 6 & (3.0 \%) & 8 & (4.1\%) & 36 & (4.2\%) & & \\
\hline Probably, will forget or & [n.a.] & [n.a.] & [n.a.] & [n.a.] & 25 & $(12.6 \%)$ & 60 & (30.1\%) & 58 & $(27.3 \%)$ & 39 & (19.6\%) & 157 & (19.2\%) & & \\
\hline
\end{tabular}

won't do

Practice 1: Exclusively breastfed infant for $\geq 6$ months, in practice

$\begin{array}{llllllllllllllllll}\text { Exclusively breastfed for } & \text { [n.a.] } & \text { [n.a.] } & 146 & (18.3 \%) & 138 & (69.1 \%) & 145 & (72.5 \%) & 153 & (73.0 & \%) & 172 & (86.1 \%) & 607 & (74.9 \%) & 519.53 & <0.001\end{array}$ $\geq 6$ months

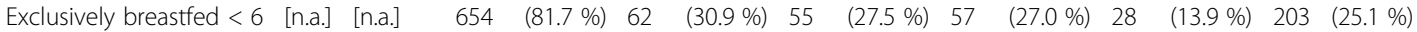
months

Practice 2: Exclusive breastfeeding recorded in MCH Handbook by mothers ${ }^{\text {a }}$

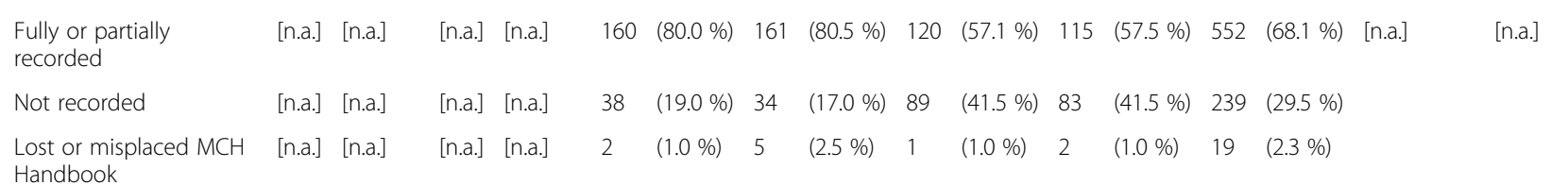

[Remarks]

${ }^{\mathrm{a}} \mathrm{MCH}-\mathrm{Handbook}$-related variables were not measured in pre-intervention, as MCH Handbooks had not been distributed. Thus, Chi-square test was not conducted between pre- and post-interventions

${ }^{\text {b}}$ The data were collected from 800 pregnant women and 800 mothers with children under three-years of age randomly sampled in Dien Bien, Hoa Binh, Thanh Hoa, and An Giang 
Seventy-six percent of pregnant women were willing to take and practically took $\mathrm{MCH}$ Handbook to commune health centers when utilizing antenatal care services. This change in attitude is likely to have contributed to the significant increase in the proportion of pregnant women who received at least three antenatal care from $67.5 \%$ in pre-intervention to $92.2 \%$ in post-intervention $(P<0.001)$. Yet, of $76.2 \%$ who brought $\mathrm{MCH}$ Handbook to commune health centers, only $66.3 \%$ had the results of antenatal care services recorded in their MCH Handbooks. One 35year old mother stated at the FGD in Thanh Hoa:

\section{Though doctors did very carefully antenatal checkup} for me, she did not record its results in my MCH Handbook maybe because of many recording items. But, I was hesitant to frankly request her to do so in front of her...

\section{KAP towards exclusive breastfeeding}

Bottom-half of Table 3 shows the KAP variables in relation to women's exclusive breastfeeding practices. The proportion of pregnant women and mothers who correctly know exclusive breastfeeding necessary for the initial six months after birth significantly increased from $66.1 \%$ in pre-intervention to $86.7 \%$ in post-intervention $(P<0.001)$. This increase is likely to be attributable to $\mathrm{MCH}$ Handbook intervention. One 22-year old mother who gave birth to her first child stated at the FGD in Hoa Binh:

\section{I sometimes read my MCH Handbook in my spare} time, as I don't have any other new books or reading materials at home. I know the recording section of the MCH Handbook is useful, but what I like best in the MCH Handbook is its guidance section. I learned that my baby needs to be only breastfed until six months old, through reading the guidance section of the MCH Handbook. A lunch event on maternal and child health was held a few months ago, but I did not participate in it, as the venue was very far. MCH Handbook is the information source good enough.... I feel somewhat routinely protected by my MCH Handbook.

Similarly to antenatal care seeking behavior, $76 \%$ of pregnant women were willing to bring and practically brought $\mathrm{MCH}$ Handbook to commune health centers when utilizing child health checkups services (incl. consultation and guidance on exclusive breastfeeding). These changes in both knowledge and attitude are likely to have contributed to the significant increase in the proportion of mothers who exclusively breastfed their children until six months years of age from $18.3 \%$ in pre-intervention to $74.9 \%$ in post-intervention $(P<0.001)$. Yet, it was observed that only $68.1 \%$ of $\mathrm{MCH}$ Handbooks had several check-boxes on exclusive breastfeeding ticked by mothers. Another 32-year old mother engaged in small-scale farming stated at the FGD in An Giang:

\section{I always take my MCH Handbook to health facility for general health checkup and immunization services of my one-year old son. Health workers professionally recorded the results of their services. Yet, once returning to my routine life in the village, I tend to grow lazy about recording the information on the pages for mother and family of the MCH Handbook. I am busy farming and taking care of three children....}

\section{Discussion}

This study confirmed the likelihood of contribution of $\mathrm{MCH}$ Handbook intervention to the increase both in antenatal care service utilizations by pregnant women and in exclusive breastfeeding practices for initial sixmonths by mothers. However, its way of contributing differs between these two types of health seeking behaviors.

Figure 1 presents the hypothetical KAP process of antenatal care service utilizations and exclusive breastfeeding practices, that was estimated in this study. Prior to $\mathrm{MCH}$ Handbook intervention, $91.9 \%$ of pregnant women in the four provinces had been already equipped with knowledge about need for three or more antenatal checkups. There was only a slight increase in the proportion of pregnant women with the knowledge after the intervention (93.7\%, $P=0.1559$ ). Thus, health workers at commune health centers must have been skilled enough to advise pregnant women to have at least three antenatal checkups at their initial visit, even without and prior to $\mathrm{MCH}$ Handbook intervention. Therefore, contribution of $\mathrm{MCH}$ Handbook intervention to the increase in knowledge of antenatal care needs is likely to have been either complementary or limited. On the other hand, the proportion of pregnant women who made three or more antenatal care visits significantly increased from $67.5 \%$ (pre-intervention) to $92.2 \%$ (post-intervention) $(P<0.001)$. This implies that $\mathrm{MCH}$ handbook is likely to have effectively encouraged pregnant women to ensure three or more antenatal care visits during pregnancy, by making their antenatal care seeking attitude more proactive (Fig. 1). Trinh et al. [16] reported that initial guidance on three-time antenatal care visits by health workers is key to continuation of antenatal care in rural Vietnam. Yet, our study implies that health workers' verbal guidance at initial antenatal care visit has limited effectiveness on their practices and that pregnant women's ownership and self-review of $\mathrm{MCH}$ Handbook further motivate them to complete three antenatal checkups. As of 2012, the mean proportion of pregnant women who made three or more antenatal care visits in 


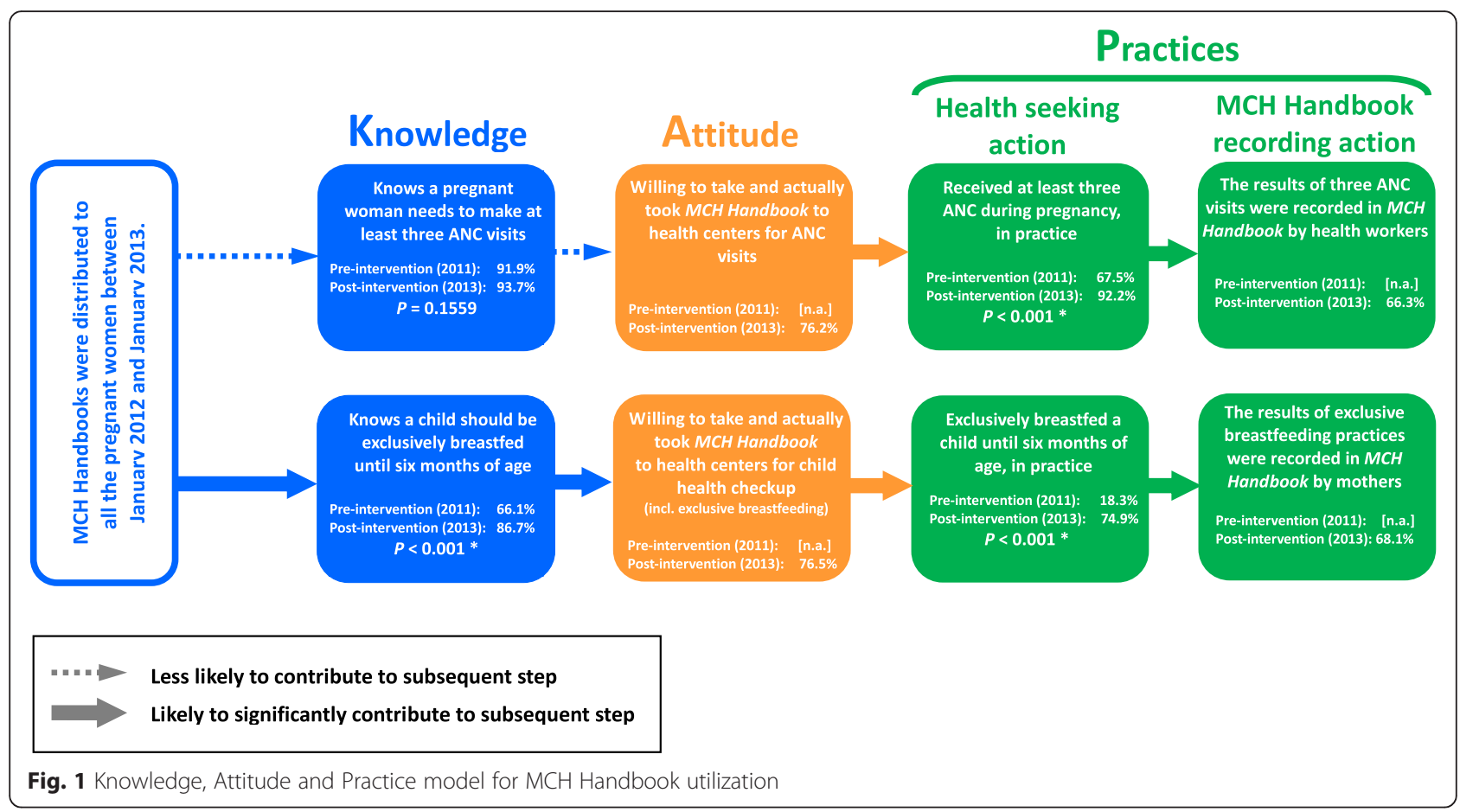

the four provinces $(76.0 \%)$ was lower than that in their nine adjacent provinces $(82.9 \%)$. Note that, however, it increased up to $92.2 \%$ in 2013 (Table 4). This figure is higher than mean proportion in the nine adjacent provinces $(82.9 \%)$ as of 2012 [17]. This may imply an increase in the proportion of pregnant women who made three or more antenatal care visits in the adjacent provinces could be expected through the introduction of $\mathrm{MCH}$ Handbook. The Vietnamese $\mathrm{MoH}$ stipulates three or more antenatal care visits [18], while WHO globally recommends four or more [19]. Application of this relaxed national standard might have been rather effective, by serving as a more realistic and friendly standard particularly for pregnant women living in the areas less accessible to health services. Without revising the national standard of necessary number of antenatal care visits, Vietnam has made a remarkable progress towards achieving MDG 5 as one of only nine on-track countries [20]. Thus, MCH Handbook will be expected to continue to play a key role in keeping pregnant women informed of this minimum requirement of antenatal care visits.

$\mathrm{MCH}$ Handbook helped significantly increase both the proportion of pregnant women and mothers who have knowledge about exclusive breastfeeding for initial six months and the proportion of mothers who practice it. One may say that not a small number of mothers might have willingly provided pleasing responses to the interviewers. To prevent these inaccurate responses, their verbal responses were double-checked against the data in breastfeeding record pages of $\mathrm{MCH}$ Handbook. Note that $68.1 \%$ of mothers recorded the results of exclusive breastfeeding practices (Fig. 1; Table 3). Moreover, when those not recording the data in $\mathrm{MCH}$ Handbook insisted their exclusive breastfeeding practices, their responses were double-checked against their family members' observations and views. Thus, the proportion of those practicing breastfeeding for initial six months is unlikely to have been overestimated. Any intervention other than $\mathrm{MCH}$ Handbook might have contributed to this increase, too. While admitting its possibilities to a certain extent, we believe $\mathrm{MCH}$ Handbook intervention is the most powerful driving force which contributed to the increase not only in knowledge but also in attitude and practices towards exclusive breastfeeding among mothers. This is because $\mathrm{MCH}$ Handbook was the only major project-type intervention in the four provinces during 1.5-year period from pre-intervention survey (December 2011-January 2012) and post-intervention surveys (July-August 2013).

In Vietnam, exclusive breastfeeding has been neither well known nor practiced until recently [21]. Therefore, home-based records such as $\mathrm{MCH}$ Handbook could serve as one of the tools which expedite exclusive breastfeeding practices by keeping mother more routinely exposed to its guidance at home. Yet, not all the mothers, particularly those less literate, do not read $\mathrm{MCH}$ Handbook by themselves as expected (e.g. the thirdly quoted FGD participant). Supplementary 
Table 4 Comparison of coverage of $\geq 3$ antenatal care visits between intervention provinces and their adjacent provinces

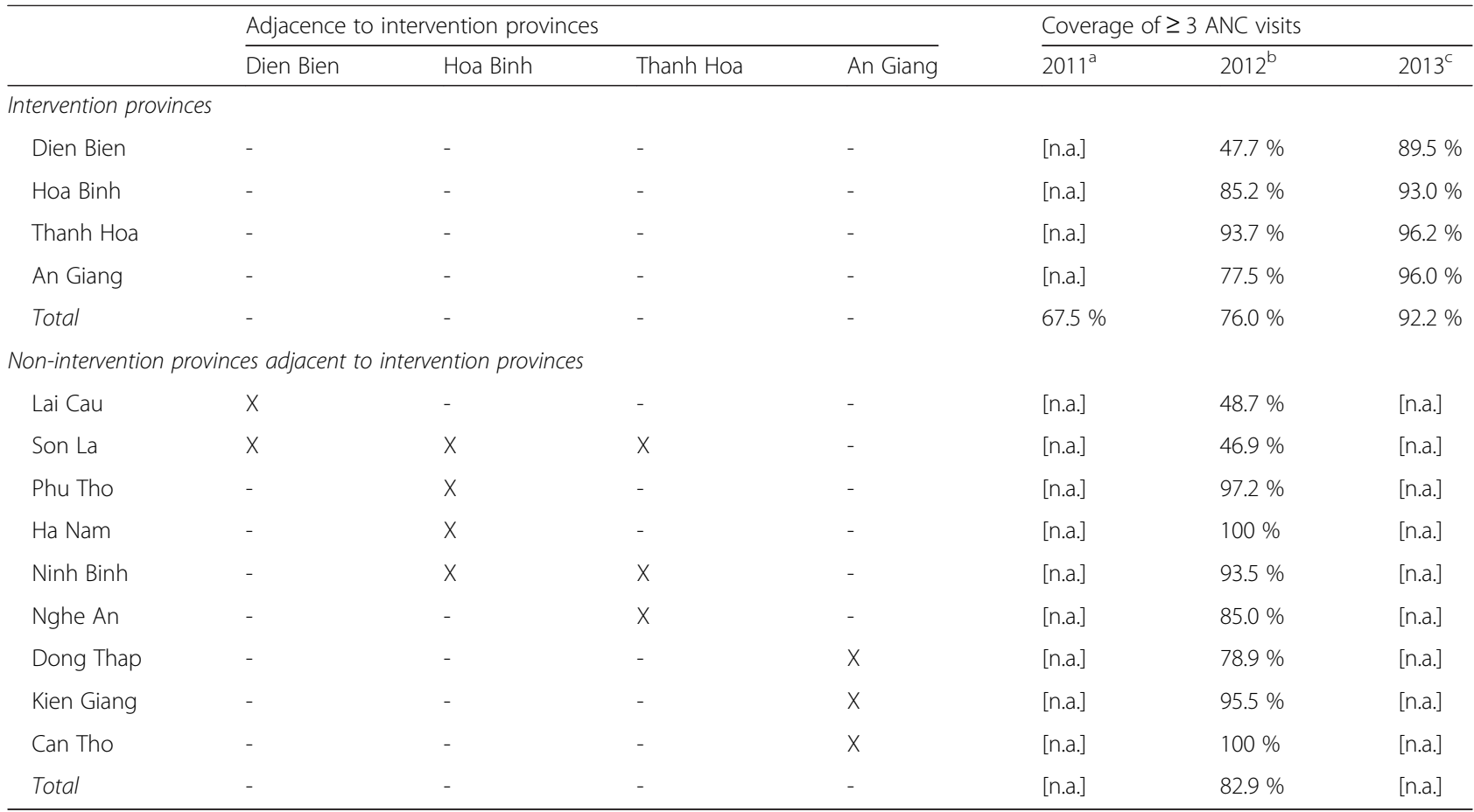

[Sources]

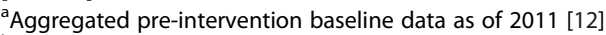

${ }^{b}$ Ministry of Health. Health Statistics Yearbook 2012. Hanoi: Ministry of Health; 2012. [17]

${ }^{c}$ Post intervention data as of 2013

behavior change communication should be the key to promoting and ensuring at-home $\mathrm{MCH}$ Handbook reading (e.g. face-to-face guidance, $\mathrm{MCH}$-related social events). Hagiwara et al. [5] reported effectiveness of $\mathrm{MCH}$ Handbook on behavior changes in exclusive breastfeeding practices among mothers in Palestine. They stressed the importance of personalized guidance on the use of $\mathrm{MCH}$ Handbook for ensuring mothers' knowledge about exclusive breastfeeding and danger signs during pregnancy.

This study has limitations in precision and generalizability of changes in mothers' KAP towards their maternal and child health seeking behaviors. Those limitations are attributed primarily to lack of consideration on counterfactual effectiveness due to absence of a control group, and also to the challenges in controlling various variables confounding with KAP due to availability of only pre-aggregated baseline data for fewer variables. This study has limitations also in precisely specifying the causality between $\mathrm{MCH}$ Handbook intervention and the increase in the KAP related to antenatal care and exclusive breastfeeding. This is primarily because this study was designed to compare between two separate cross-sectional datasets of pre- and post-interventions. To address these limitations, either a randomized control trial or at least a longitudinal cohort study is necessary.

\section{Conclusion}

The results of study imply that MCH Handbook contributed to the increase in pregnant women's practices of three or more antenatal care visits and in both knowledge about and practice of exclusive breastfeeding. While there is room for improvement in the level of data recording in it, the study confirmed that $\mathrm{MCH}$ Handbook plays a catalytic role in ensuring a continuum of maternal, newborn and child care.

In Vietnam, numerous home-based records for maternal and child health have been implemented in many parts of the country in a fragmented manner [22]. Therefore, it is an urgent task to standardize and integrate those currently existing home-based records into one. To address the issue, the Vietnamese $\mathrm{MoH}$ announced that the $\mathrm{MCH}$ Handbook piloted in the four provinces should be nationally scaled up as a single nationally standardized MCH home-based record, in August 2015. As MCH Handbook needs to be distributed to 1 million newly pregnant women per annum in the entire country, a national strategic plan for $\mathrm{MCH}$ Handbook operation should be carefully developed to ensure its operational sustainability.

There has been no reported case that attempted to estimate effectiveness and impact of home-based record 
intervention in Vietnam. In this respect, this study serves as the critical initial milestone for the future $\mathrm{MCH}$ home-based record deployment in the country.

\section{Competing interests}

The authors declare that they have no competing interests.

\section{Authors' contribution}

All the authors made substantial intellectual contributions to the study. HA and NDV conceptualized and designed the study. HA, NDC, NTTT, and NTPL collected, analyzed, and interpreted the data. HA drafted and finalized the manuscript. All the authors read and approved the final version of the manuscript.

\section{Acknowledgments}

The authors gratefully thank Keiko Osaki, Akiko Hagiwara and Tomoya Masaki for their valuable technical supports and comments. The authors also thank the Ministry of Health, of Socialist Republic of Vietnam, and Japan International Cooperation Agency (JICA) for their funding support to the study. A word of special thanks is delivered to Vi Thi Hoa of Dien Bien Provincial Department of Health, Hoang Thi Thuy of Hoa Binh Provincial Department of Health, Do Quang Vinh of Thanh Hoa Provincial Department of Health, and Trinh Huu Tho of An Gian Provincial Department of Health for their tremendous support to data collection. This work is sincerely dedicated to the late Dr. Tran Huynh Phu Hung, and all the pregnant women, mothers and children in Vietnam.

\section{Author details}

'Human Development Department, Japan International Cooperation Agency (JICA), 3rd floor, Nibancho Center Building, 5-25 Niban-cho, Chiyoda-ku, Tokyo 102-8012, Japan. ${ }^{2}$ Department of Global Health, Milken Institute School of Public Health, The George Washington University, 950 New Hampshire Ave, NW, 7th floor, Washington DC 20052, USA. ${ }^{3}$ Maternal and Child Health Department, Ministry of Health, 138A Giang Vo, Ba Dinh district, Hanoi, Vietnam. ${ }^{4}$ Sustainable Health Development Center, VietHealth, 16, Block 13B, Trung Yen 11, Cau Giay district, Hanoi, Vietnam. ${ }^{5}$ Department of Community Health \& Preventive Medicine Network Coordination, National Institute of Hygiene and Epidemiology, 1 Yersin, Hai Ba Trung district, Hanoi, Vietnam.

Received: 17 July 2015 Accepted: 27 January 2016

Published online: 09 February 2016

\section{References}

1. Osaki K, Hattori T, Kosen S. The role of home-based records in the establishment of a continuum of care for mothers, newborns, and children in Indonesia. Glob Health Action. 2013:6:1-12.

2. Osaki $\mathrm{K}$, Hattori T, Kosen S. Factors affecting the utilisation of maternal, newborn, and child health services in Indonesia: the role of the Maternal and Child Health Handbook. Public Health. 2015;129(5):582-6.

3. Kusumayati A, Nakamura Y. Increased utilization of maternal health services by mothers using maternal and child health handbook in Indonesia. J Int Health. 2007;22(3):143-51.

4. Bhuiyan SU, Nakamura Y. Continuity of maternal, neonatal and child health care through MCH handbook for ensuring the quality of life. $2008 \mathrm{MCH}$ handbook conference report. Suita: Osaka University; 2009.

5. Hagiwara A, Ueyama M, Ramlawi A, Sawada Y. Is the Maternal and Child Health $(\mathrm{MCH})$ handbook effective in improving health-related behavior? Evidence from Palestine. J Public Health Policy. 2013;34(1):31-45.

6. UNICEF. The state of the World's Children Report 2015. New York: UNICEF; 2015

7. Ministry of Planning and Investment. The 1/4/2013 time-point population change and family planning survey- major findings. annex 9. Hanoi: Ministry of Planning and Investment; 2013. http://www.gso.gov.vn. Accessed 15 Jul 2015.

8. Ministry of Health. Annual report of provincial health services. Hanoi: Ministry of Health; 2015.

9. General Statistics Office of Vietnam. Statistical data for population and employment. Hanoi: General Statistics Office of Vietnam; 2015. http://www. gso.gov.vn. Accessed 15 Jul 2015.
10. Central Population Housing Census Steering Committee. The 2009 Vietnam Population and Housing Cencus. Central Population and Housing Census Steering Committee: Hanoi; 2010.

11. Ministry of Labor, Invalids and Social Affairs, Hanoi. Decision no. 529 on 05/06/ 2014 - approving the result of survey, revision on poor household and near poor household in 2013. Hanoi: Ministry of Labor, Invalids and Social Affairs; 2013.

12. Research Center for Rural Population and Health. Baseline survey for the project of pilot implementation of maternal and child health handbook in Dien Bien, Hoa Binh, Thanh Hoa and An Giang provinces. Hanoi: JICA \& MoH; 2012.

13. WHO. Service Availability and Readiness Assessment (SARA): an annual monitoring system for service delivery, Reference Manual. Geneva: WHO; 2014. p. 23-4.

14. VietHealth. Report of end-line survey for assessing the intervention of the maternal and child health handbook. Hanoi: JICA \& MoH; 2013. p. 24.

15. du Monde M. Data collection, quantitative methods: KAP survey model. Saint-Etienne: IGC Communigraphie; 2011.

16. Trinh LT, Dibley MJ, Byles J. Determinants of antenatal care utilization in three rural areas of Vietnam. Public Health Nurs. 2007;24(4):300-10.

17. Ministry of Health. Health statistics yearbook 2012. Hanoi: Ministry of Health; 2012.

18. Ministry of Health. National clinical guidelines on reproductive health care services. Hanoi: Ministry of Health; 2009.

19. Partnership for Maternal, Newborn and Child Health. Opportunities for Africa's newborns practical data, policy and programmatic support for newborn care in Africa. Geneva: WHO; 2006.

20. WHO, UNICEF. Countdown to 2015 Building a future for women and children: the 2012 report. Geneva: WHO; 2012

21. Almroth S, Arts M, Quang ND, Hoa PT, Williams C. Exclusive breastfeeding in Vietnam: an attainable goal. Acta Paediatr. 2008;97(8):1066-9.

22. Aiga H, Nguyen DV, Nguyen DC, Nguyen TT. Nguyen TPL. Fragmented implementations of maternal and child health home-based records in Vietnam: Need for an integration. Glob Health Action (in press).

\section{Submit your next manuscript to BioMed Central and we will help you at every step:}

- We accept pre-submission inquiries

- Our selector tool helps you to find the most relevant journal

- We provide round the clock customer support

- Convenient online submission

- Thorough peer review

- Inclusion in PubMed and all major indexing services

- Maximum visibility for your research

Submit your manuscript at www.biomedcentral.com/submit
BioMed Central 